\title{
Lahire, Bernard. L'interprétation sociologique des rêves. Paris : La découverte, 2018
}

\author{
Marc Barbeta Viñas \\ Universitat Autònoma de Barcelona / Universitat de Girona, España \\ marc.barbeta@gmail.com
}

Propuestas teóricas recientes han situado el individuo en el centro de sus explicaciones desde el compromiso de no desocializar, en todos los niveles, el enfoque sociológico. Un ejemplo de ello es la perspectiva contextual disposicionalista desarrollada por el sociólogo francés de l'École Normale Superior de Lyon Bernard Lahire. En una de sus últimas publicaciones, la obra que aquí reseñamos, utiliza este modelo para analizar desde una perspectiva sociológica el fascinante y misterioso fenómeno de los sueños.

En este libro, publicado en francés, Lahire nos propone una sugerente aproximación a lo que él mismo define como un programa de investigación dedicado a la sociología de los sueños. El embrión de dicha empresa se gestó en una estancia de investigación que el propio Lahire realizó en la Universidad de Berkeley, donde entró en contacto con investigadores y textos que desarrollaban esta poco habitual línea de investigación. Pasados más de 20 años de aquel primer contacto y del inicio de su interés por el sueño como objeto de estudio, el trabajo de investigación y lectura ha empezado a dar sus frutos: el monumental libro - de casi 500 páginas- que presentamos. Se trata de un proyecto que debe entenderse y se presenta en dos tiempos, dando lugar a dos obras distintas, aunque estrechamente relacionadas. La primera de ellas es la obra ya publicada a la que nos referimos con el presente comentario. Una obra que pretende ser el momento experimental de la construcción teórica y metodológica empíricamente fundada del objeto (la construcción de un modelo teórico a partir de material empírico acumulado y de revisión bibliográfica). La segunda, cuya publicación se prevé para 2021, respondería al momento de análisis sistemático de material empírico, que pondría "a prueba" el modelo inicialmente planteado.

Lahire pretende una aproximación científica al fenómeno de los sueños; y lo que presenta es una enorme discusión entre los distintos paradigmas y disciplinas que han estudiado el sueño, para terminar proponiendo un modelo teórico con capacidad de dar cuenta, en términos sociológicos, de los procesos y dinámicas de producción onírica. Pero Lahire apuesta por ir más allá de las escasas aportaciones realizadas desde la sociología (aunque con excepciones como las de Roger Bastide, Maurice Halbwachs...). Frente a la estrategia de la producción de conocimiento por la vía de la especialización, el autor apuesta por una vía de síntesis y articulación que hace del modelo sociológico un modelo integrador, clarificador y colaborativo entre distintas aportaciones. Así no deja de tener en cuenta los diálogos posibles y los descubrimientos de la psicología y la neurología del sueño y del dormir.

La vocación científica del proyecto toma, además, dos orientaciones fundamentales. Una, Lahire piensa que el avance en la producción de conocimiento pide una posición intermedia entre el dogmatismo y el relativismo científico. Apuesta por abordar el proceso 
de producción del sueño en cuanto tal, no solamente apropiaciones narrativas (relativistas) del mismo, aunque sin olvidar la influencia del contexto social en la producción del conocimiento. La otra, rechaza aproximaciones puramente especulativas entre las que cita la fenomenología de Schütz, para enrolarse en una aproximación que articule teoría y empiria a través de una metodología específica.

Siguiendo los pasos de Freud, el autor francés apuesta por desarrollar una interpretación científica de los sueños, como nos indica el título de la obra. Se trata de una hipótesis de trabajo que consiste en asumir que los sueños no son un flujo aleatorio e incoherente de imágenes, sensaciones...que no dependen de ningún marco regulatorio ni lógica de organización. Así Lahire sitúa su interés por los sueños más cerca del sentido y la coherencia, siguiendo una tradición que según afirma es incluso anterior a Freud. Evidentemente, esta hipótesis supone mantener ciertas distancias con los dogmatismos neurocientíficos (que no todos los son) que niegan la posibilidad de interpretar nada en un sueño, y que reducen el fenómeno a excitaciones y actividad de ciertas zonas del cerebro. Apoyándose en distintas publicaciones Lahire rechaza el "mito" de la correspondencia del sueño y la fase REM: esta idea se usaría para explicar el sueño solamente a partir de mecanismos neuronales y fisiológicos del cerebro. Lahire defiende que los sueños no están solamente vinculados a una fase del dormir. El estado de ensoñación puede ser condición para la aparición de imágenes y sensaciones, pero éstas no pueden reducirse a los mecanismos del cerebro. Desde el respeto a los distintos niveles de la realidad, Lahire defiende que igual como un sociólogo, para dar cuenta de sus objetos de estudio, no necesita de un físico o un biólogo que den cuenta de los átomos y los niveles celulares de la vida humana, es legítimo analizar los sueños a partir de su rememoración en forma de relato. Los esquemas, disposiciones y competencias que se ponen en práctica en la producción de los sueños dificilmente pueden estudiarse desde las neurociencias; pero ello no significa poner en cuestión las condiciones de posibilidad biológicas de los fenómenos sociales. El autor contempla aquello que le ocurre al cerbero durante el estado de ensoñación: desactivación del cortex prefrontal y falta de control del pensamiento racional, etc. Sin embargo, ésta es una característica común a todo ser humano y, en cambio, no todos los humanos soñamos lo mismo ni de la misma manera. La apuesta fuerte de Lahire es, entonces, la posibilidad de interpretar el sentido de un sueño atendiendo a sus capacidades simbólicas, adquiridas cultualmente, a través de experiencias sociales y emocionales.

En la revisión de la literatura en ciencias sociales, aun reconociendo ciertos avances, se constatan distintos problemas a resolver en las aportaciones existentes; ya sean interaccionistas, de la ecología de los sueños o de autores clásicos como Le Goff, Burke, o el mismo Halbwachs. Los análisis de contenido cuantitativos de los sueños reciben también fuertes objeciones. A pesar de las posibilidades incuestionables de relacionar sueños con variables sociodemográficas, la estadística no deja de ser inútil en la tarea de estudiar formaciones simbólicas, metáforas, etc., pues no permite analizar el sentido global del sueño y los elementos "ocultos" que lo configuran.

A la confrontación con el psicoanálisis, en particular con la obra de Freud, siendo una constante del libro, dedica Lahire un capítulo entero. Como afirma el autor, la obra está escrita con Freud y contra Freud, en un intento de aprovechar las aportaciones relevantes del vienés, pero a la vez, rechazando una parte importante de sus tesis. Algunas de las críticas van dirigidas al supuesto biologismo, al universalismo de determinados procesos, la apelación a herencias arcaicas, al familiarismo y, con ello, a la explicación infantilista y sexualizada del origen de los sueños. Concretamente Lahire discute la tesis central de Freud según la cual los sueños serían solamente la expresión de deseos inconscientes, engendrados en la niñez. No dice que ello no sea posible, pero que todo se reduzca a esta explicación es lo que parece razonable que no acepte el autor francés. Lahire, sin embargo, 
a pesar de hacer referencia en otros capítulos a psicoanalistas más actuales, elude avances que desde el mismo psicoanálisis se han hecho, justamente, en estas cuestiones. Para Lahire, en Freud parece perderse lo social, o reducirse a las relaciones interpersonales de la vida infantil. Sin embargo, y a pesar de ser cierto que Freud no se ocupa del impacto de la estructura social, mejor sería decir que en Freud el conflicto social se interioriza. Como alternativa a la sexualización de los sueños Lahire propone una "dimensión política" a la configuración de los sueños, introduciendo como elementos centrales las relaciones de poder y dominación presentes en cualquier experiencia social. Los trabajos sobre sueños en regímenes totalitarios de Beradt, o la expresión de sentimientos de grandeza, ambición, etc. del neuropsiquiatra J. A. Hobson serían ejemplos de ello.

Otro distanciamiento respecto las tesis freudianas es la cuestión de la censura y su papel en el sueño, vinculado a la tesis del inconsciente dinámico descubierto por Freud. Estratégicamente se apoya en distintos autores que defienden esta postura. Lahire no niega el carácter inconsciente de buena parte de los motivos y la formación del sueño; de hecho defiende, con sólidos argumentos, que el sueño es de naturaleza "involuntaria", "irreflexiva" además de inconsciente, por más que el soñante pueda recordar algunos aspectos del sueño. El inconsciente defendido por Lahire, coherente con su modelo disposicionalista, se acerca más a la idea de pasado incorporado. Eso es, la consideración del sedimento que dejan las experiencias de socialización, que constituyen la base de los esquemas y disposiciones que orientan la producción onírica. Así nuestro autor utiliza un concepto de inconsciente procedimental crecientemente aceptado por distintas disciplinas científicas, también el psicoanálisis. La ventaja, en este caso, sería que se trata de un inconsciente que no necesita de la tesis de la represión y la censura, por lo que los sueños podrían explicarse sin acudir a este tipo de hipótesis. Para Lahire, estas ideas, además de llevar implícito un sesgo moral y político que juzga como propio de la época de Freud, conllevan notables incoherencias. La censura sería el mecanismo que impone la necesidad en el sueño de deformarse, volverse incoherente, no obstante, cuando se duerme la censura queda relajada; de modo que cuesta argumentar que continúe imponiendo procesos de disimulación. La explicación alternativa de Lahire al encriptamiento de los sueños, si bien es sugerente, tampoco parece una tesis definitiva. La clave estaría en las relaciones de dominación, de acuerdo a las aportaciones de J. Scott y P. Bourdieu sobre los comportamientos discursivos. En resumen, el sueño se situaría en el polo de los "textos privados", ocultos, que no necesitarían legitimación ninguna como sí ocurre en los espacios públicos. De manera que cuando se sueña se hace con sistemas de valores y trasfondos existenciales propios, que no deben legitimarse, siendo la expresión más pura de uno mismo: el sueño sería expresión incontrolada, visceral.

Por esta vía se llega a una definición que, ciertamente, ofrece mayor compatibilidad con el estado de conocimiento sobre el objeto en distintas disciplinas, también la psicoanalítica: el sueño sería la expresión simbólica particularmente "lucida y perspicaz" de "problemáticas existenciales" del soñante. Los sueños serían la expresión onírica de problemas, preocupaciones, sucesos que tienen los individuos en su vida cotidiana, en los distintos escenarios, situaciones y contextos sociales donde se desarrollan. Estos problemas, se insiste en el libro, generadores de malestares, sufrimientos y que encuentran su origen en conflictos no resueltos, tensiones, aspiraciones o deseos frustrados, anticipaciones de situaciones angustiantes, etc., no solamente tendrían relación con la configuración familiar (que a veces también), sino que podrian reaparecer en distintas etapas de la vida. De la mano de Thomas M. French, Lahire define el sueño como una "estructura cognitiva" susceptible de expresar un "problema focal". La interpretación pasaría así por hallar esta problemática no resuelta en cada sueño y reconstruir los ecos sociales y afectivos que tiene con el pasado en una visión similar a la del psicólogo Phillip 
Malrieu a quien, curiosamente, no se cita. En línea con lo que pasa en diferentes corrientes actuales, Lahire abre el espectro afectivo implicado en los sueños, de tal manera que las emociones -y no solo el deseo- operan como fuerzas motrices del sueño. No se trata, sin embargo, de emociones "flotantes", en abstracto, sino singulares, vinculadas a situaciones concretas de la vida de las personas. Cuando se sueña no se hace con el miedo en general, sino el miedo concreto que experimentamos ante determinada situación. Así el sueño funciona a través de un poderoso mecanismo de analogía mediante el cual el soñante asocia, por transferencia o por contigüidad, realidades distintas, incluso conectando el presente con el pasado incorporado. Pero que éste sea su funcionamiento no significa, nos dice Lahire en la conclusión, que se pueda atribuir una "función" al sueño.

Lahire enfoca los sueños en su vinculación con lo social como una forma de expresión que deviene el entramado de múltiples experiencias sociales, pasadas y presentes, moduladas por prácticas lingüísticas. Lo social no es sinónimo solamente de lo colectivo, sino de la producción de sujetos sometidos a procesos de socialización. Y por esta vía entronca con su modelo disposicionalista contextualista con el que se interpreta el sueño a partir de su relato y las articulaciones con disposiciones incorporadas durante la biografía del soñante que el mismo sueño revela. La naturaleza individual pero socialmente producida del sueño posibilita entonces un abordaje sociológico a partir de la reconstrucción de los esquemas de experiencia que el soñador pone en juego en el sueño, producidos en su historia social y biográfica, y reactivados a partir de de situaciones vividas en el transcurso de la vida social. El modelo básico: disposiciones (pasado incorporado)-contexto de acción (presente)-prácticas, se transforma en tres momentos al entorno del sueño cuyo análisis se hace imprescindible para su interpretación: etapa presueño (disposiciones, esquemas inconscientes del pasado...); etapa del sueño (analogías pasado-presente y mecanismos del sueño); etapa post-sueño y su relato (relato articulador de lo anterior por parte del actor en un contexto vivencial presente). Sin duda, un modelo integrador que busca analizar el carácter sobredeterminado de la formación de todo sueño. Desde los elementos estructurales de la personalidad del soñante, elementos estructurantes vinculados a la problemática central del sueño, estímulos, restos diurnos y elementos desencadenantes, además de la tarea fundamental a la que Lahire dedica un largo capítulo: analizar las "operaciones oníricas". Aunque con matices y novedades, aquí sigue los mecanismos freudianos del sueño: la visualización y el carácter simbólico, la metaforización, la condensación, la inversión u oposición... pero siempre desde una perspectiva personal concreta, en lo que define el mismo autor como una sociología de las variaciones intra-individuales del comportamiento expresivo.

Lahire dedica hacia el final del libro un capítulo a la metodología de análisis de los sueños. El método se inscribe dentro del cualitativismo que toma el relato de los sueños como un texto. Un texto que se interpreta a partir de las asociaciones del soñante -como en Freud- pero también poniéndola en relación con una "biografia sociológica" consistente en investigar los vínculos y experiencias socializadoras de los soñantes en sus distintos escenarios de vida. Lahire incluso redacta un pequeño protocolo de pasos a seguir, cuya información debe ir completándose con la recolección de los relatos de los sueños y sucesivas entrevistas a los soñantes hasta llegar a las lógicas y esquemas de creación singular de sueños particulares. El notable afán comprensivo de esta empresa se revela como un laborioso trabajo que puede conllevar dificultades en su desarrollo empírico: la no siempre fácil rememoración de los sueños, grandes volúmenes de información, consideración de múltiples factores condicionantes, etc.

Al fin, se trata de un libro original, que desvela un trabajo ingente por parte del autor y que acerca la disciplina sociológica a un objeto denso, complejo e inequívocamente vinculado con lo social. Sin embargo, si en Freud el análisis de los sueños tenía como 
finalidad ampliar el conocimiento del funcionamiento de lo inconsciente, ¿qué nos aporta en sociología el estudio de los sueños? Tal vez esté menos claro que en Freud, pero de acuerdo con la lectura, podríamos decir que nos aporta información, justamente, sobre cómo distintos niveles de lo social y lo histórico cristalizan en y configuran los individuos. En un ejercicio de excesiva ambición, Lahire vincula además su sociología de los sueños con efectos terapéuticos y políticos, asumiendo que buena parte de los problemas personales son, al mismo tiempo, colectivos. 